\title{
Desafios dos coordenadores pedagógicos de São Caetano do Sul, ABC Paulista: um estudo baseado na pesquisa-ação colaborativa
}

\author{
Challenges of head teachers of São Caetano do Sul, ABC Paulista:
}

a study based on collaborative action research

\section{Desafíos de los coordinadores pedagógicos de São Caetano do Sul, ABC Paulista: un estudio basado en la investigación-acción colaborativa}

\author{
Vanessa Maria Vicente Umemura ${ }^{1}$ \\ Sanny Silva da Rosa ${ }^{1}$
}

\begin{abstract}
Recebido em 20/04/2018; revisado e aprovado em 30/09/2018; aceito em 28/10/2018.
\end{abstract}
DOI: http://dx.doi.org/10.20435/inter.v21i1.1941

\begin{abstract}
Resumo: Este artigo apresenta resultados de uma pesquisa-ação realizada no município de São Caetano do Sul, com o objetivo de fortalecer a gestão democrática da escola em prol da qualidade social da educação. Discute os desafios do trabalho do coordenador pedagógico no contexto das políticas regulatórias do estado. Conclui que é necessário e possível abrir espaços de diálogo e participação dos docentes na tomada de decisões sobre os rumos da escola.
\end{abstract}

Palavras-chave: coordenador pedagógico; gestão democrática; pesquisa-ação; qualidade social da educação.

Abstract: This article presents the findings of an action research conducted in São Caetano do Sul, in order to strengthen the democratic school management for social quality of education. It discusses the challenges of the head teacher's work in the context of the state's regulatory policies. It concludes that it is necessary and possible to open spaces for dialogue and participation of teachers in decision-making on school routes.

Keywords: teaching asssistant; democratic management; action research; social quality of education.

Resumen: Este artículo presenta resultados de una investigación-acción realizada en el municipio de São Caetano do Sul, con el objetivo de fortalecer la gestión democrática de la escuela en pro de la calidad social de la educación. Discute los desafíos del trabajo del coordinador pedagógico en el contexto de las políticas regulatorias del estado. Concluye que es necesario y posible abrir espacios de diálogo y participación de los docentes en la toma de decisiones sobre los rumbos de la escuela.

Palabras clave: coordinador pedagógico; gestión democrática; investigación-acción; calidad social de la educación.

\section{INTRODUÇÃO}

Na busca incessante por melhores resultados, professores têm sido tratados como executores e os gestores como fiscalizadores das políticas estabelecidas pelos órgãos centrais da administração pública de educação. Na onda das reformas globais, intensificadas a partir dos anos 2000, as "propostas" pedagógicas e de formação docente, em geral, chegam às escolas como pacotes a serem implementados, passando por cima de sua história e desconsiderando os contextos e as necessidades locais.

Concepções da administração empresarial, consistentemente criticadas (ARROYO, 1979; FÉLIX, 1984 PARO, 2016), hoje materializam-se na rotina escolar, por meio de estratégias mais "eficazes" de gestão para o alcance de "bons resultados". Embora os discursos pedagógicos oficiais proponham que escola defina o seu projeto político-pedagógico, a pressão exercida para o cumprimento de metas ancoradas nas matrizes de testes padronizados restringe, na prática, a sua autonomia. Os efeitos de tais pressões se fazem sentir nas práticas docentes e na gestão pedagógica, modificando o sentido do trabalho de diretores, coordenadores e professores.

\footnotetext{
${ }^{1}$ Universidade Municipal de São Caetano do Sul (USCS), São Caetano do Sul, São Paulo, Brasil.
} 
Na perspectiva do que alguns autores (BALL, 2012; ANDERSON, 2017) têm chamado de nova gestão pública (NGP), a presença cada vez maior de atores do setor privado na condução de políticas educacionais, como institutos, fundações e organizações filantrópicas, vai redesenhando a visão de mundo dos profissionais de educação ao modo de pensar desses empreendedores. Preocupações com a "eficácia" e "eficiência" dos processos, o recurso a modelos de "boas práticas", a adesão a fórmulas meritocráticas e o deixar-se seduzir pelas políticas de recompensas são exemplos de como tais concepções têm logrado forjar uma nova noção de profissionalismo entre os educadores.

Sensível às auditorias e obediente às regras e aos critérios de qualidade definidos externamente, esse novo profissionalismo só é reconhecido quando testado e convertido em medidas e indicadores quantificáveis. De acordo com Ball (2005, p. 541), são essas características que distinguem o "profissionalismo pós-moderno" - ou o "pós-profissionalismo" - do profissionalismo autêntico, que tinha "como base o valor da reflexão e a possibilidade de indecisão" diante das contingências. A visão corporativa nega as complexidades do real e opera com um conceito fixo e linear de qualidade, no qual não têm lugar ou valor inúmeros outros aspectos da vida escolar e das condições concretas com as quais alunos, professores e gestores têm de se haver para dar conta das exigências que lhes são impostas.

Frustrando, porém, as expectativas dessa visão simplista e simplificadora, a escola é inapelavelmente palco de conflitos e contradições. Se, por um lado, é certo que os profissionais são pressionados a atender as demandas externas, de outro, eles são confrontados e sentem na pele os efeitos da impossibilidade de cumpri-las ipsis litteris. A intensificação do trabalho docente, o estrangulamento do tempo e a exiguidade de espaços institucionalizados onde possam expressar e compartilhar suas fragilidades, incertezas e também as experiências bem-sucedidas são elementos que, quando postos em questão, predispõem esses profissionais à participação, ao diálogo e à reflexão.

Diante desse cenário, este artigo relata e discute uma pesquisa-ação colaborativa, realizada nos anos de 2016 e 2017, em uma escola de Ensino Fundamental (EF) da rede de ensino de São Caetano do Sul, região do Grande ABC Paulista. As inquietações que deram origem a este estudo, desenvolvido no âmbito de um mestrado profissional em educação, relacionam-se diretamente ao trabalho do coordenador pedagógico, responsável pela articulação do trabalho do corpo docente que, em tese, tem como referência o projeto político-pedagógico da escola.

Mas de que projeto educativo estamos falando? Que valor tem esse documento - em geral esquecido - quando o tempo da escola é preenchido quase que totalmente com atividades voltadas às avaliações externas? É seguro que essas avaliações medem a qualidade de nosso trabalho? De que qualidade estamos falando? A qualidade almejada leva em conta as necessidades e prioridades da escola? Diante de tantas interrogações, para as quais não temos respostas, nem mesmo provisórias, o que se espera do coordenador pedagógico? Como lidar com as tensões entre as crescentes atribuições prescritivas do cargo e a obediência aos princípios da gestão democrática também dele esperados? Por fim, o que é e como se conduz uma gestão democrática?

Indagações como essas, entre outras que foram surgindo no delineamento da pesquisa, desafiaram-nos a pavimentar um caminho alternativo de trabalho da coordenação pedagógica na escola em que, então, atuávamos. Tínhamos em mente criar e fortalecer mecanismos de participação e diálogo, bem como desenvolver uma cultura de reflexão e de trabalho colaborativo entre os docentes e a equipe gestora. Daí optarmos por realizar uma pesquisa-ação colaborativa 
(IBIAPINA, 2008), cuja base epistemológica e metodológica pressupõe que os professores não são nem objetos nem meros alvos das pesquisas acadêmicas. Nossa intenção era construir esse caminho com eles, e não para eles, o que implicava chamá-los a problematizar as práticas da escola e redefinir, juntos, princípios e ações para um trabalho pedagógico efetivamente colaborativo.

A pesquisa-ação não é uma modalidade nova. As primeiras investigações desse tipo foram realizadas no campo da psicologia social, por Kurt Lewin (1890-1947), no contexto da Segunda Guerra Mundial. Na educação, consolidou-se a partir da década de 1980, com as experiências de autores como Carr e Kemmis (1988), Zeichner (1993) e Freire (1997). Em tempos em que o projeto democrático se fragiliza em muitas partes do mundo, particularmente no Brasil, os princípios fundamentais da pesquisa-ação emancipatória permanecem não só atuais como necessários.

Com o objetivo de compartilhar nossa experiência, este artigo foi dividido em três partes complementares. Na primeira, procuramos argumentar que, quando as avaliações externas se transformam no eixo norteador da vida escolar, coloca-se em risco a gestão democrática e a qualidade social da educação. Na segunda, buscamos expor que o papel atribuído ao coordenador pedagógico no contexto de políticas prescritivas de avaliação e currículo entra em choque com a autêntica finalidade de sua função. Por fim, com base na análise dos registros das sessões reflexivas, procuramos destacar, de um lado, como as marcas da concepção produtivista de educação estão presentes nos significados e sentidos atribuídos pelos participantes ao seu próprio trabalho e, de outro, os desafios colocados ao coordenador pedagógico como mediador das relações democráticas dentro da escola.

\section{AVALIAÇÕES EXTERNAS E OS RISCOS PARA QUALIDADE DA ESCOLA}

Os ciclos nacionais de avaliação foram instituídos com o argumento de que ajudariam a melhorar a qualidade da educação básica, principalmente das escolas públicas do país. Inspiradas nas diretrizes educacionais emanadas da Organização para Cooperação e Desenvolvimento Econômico (OCDE), as avaliações de larga escala no Brasil se converteram na grande razão de ser da vida escolar, o que, paradoxalmente, se transformou em grande armadilha e ameaça à qualidade almejada.

Segundo Bonamino e Sousa (2012), o Brasil já passou por três gerações de avaliação, as quais trouxeram progressivas consequências para o currículo, para a dinâmica do trabalho escolar e para a gestão dos sistemas educacionais. Segundo as autoras, as avaliações da primeira geração produziram efeitos brandos, pois traziam dados amostrais com função eminentemente diagnóstica. A partir de 2007, porém, as avaliações censitárias de segunda geração, como a Prova Brasil, passaram a responsabilizar a escola pelos resultados, gerando consequências simbólicas aos profissionais envolvidos.

É que, com a régua do Indicador de Desenvolvimento da Educação Básica (IDEB) e com o auxílio da mídia, cada unidade de ensino passou a ser julgada em função de sua posição no ranking das "melhores" e "piores" escolas. Como desdobramento desse modelo, a terceira geração de avaliação acrescentou, aos efeitos da segunda, consequências materiais aos profissionais da educação. Um bom exemplo é a política de bônus por mérito, instituída em 2007 pelo governo do estado de São Paulo, com base no Índice de Desenvolvimento da Educação de São Paulo (IDESP), também adotada por diversos outros estados e municípios brasileiros. 
Como consequência, muitas escolas passaram a "adiantar" conteúdos que seriam trabalhados ao longo do ano a fim de ajustá-los ao calendário das avaliações. Os riscos para o currículo resultantes dessa responsabilização forte são apontados por Bonamino e Souza (2012, p. 383):

[...] evidências nacionais e internacionais mostram que principalmente o uso de resultados das avaliações da terceira geração para informar iniciativas de responsabilização forte pode envolver riscos para o currículo escolar. Um deles é a situação conhecida como ensinar para o teste, que ocorre quando os professores concentram seus esforços preferencialmente nos tópicos que são avaliados e desconsideram aspectos importantes do currículo, inclusive de caráter não cognitivo.

No município de São Caetano do Sul, locus desta investigação, além das provas nacionais e estaduais, os alunos do Ensino Fundamental também fazem a Prova São Caetano. Esta prova, aplicada três vezes ao ano, desde 2013, tem o objetivo de acompanhar o desempenho da rede em Língua Portuguesa e Matemática, assim como nortear o planejamento de ações formativas da Secretaria de Educação do município aos docentes da rede. Os resultados são apresentados diretamente às escolas, para que definam planos de ação específicos em cada unidade de ensino.

Embora as avaliações possuam potencial para contribuir para a melhoria da qualidade da educação, estudos já apontaram que "[...] a forma de divulgar este material e a própria curiosidade de verificação dos resultados de outros estabelecimentos ou esferas pode [sic] gerar distorções nos objetivos do processo" (SOLIGO, 2010 p. 6). Na mesma linha de raciocínio, Vidal e Vieira (2011) reconhecem que a existência de uma base de dados pode ser valiosa como instrumento de gestão, mas argumentam que a divulgação de resultados de forma inapropriada interfere e modifica a prática das escolas.

Assim, não há como discordar de Luís Carlos Freitas (2014) quando diz que as políticas meritocráticas e de responsabilização distorcem as referências do que seja uma educação de qualidade. Mais que isso, reforçam no imaginário social a pertinência do controle externo sobre a "produtividade" das escolas, prática que passou a ser vista como boa e até natural. Passados mais de vinte anos da promulgação da LDB - lei que tem como um de seus princípios basilares a gestão democrática -, o que se vê, ao contrário, é que predominam nas escolas práticas de gestão fortemente diretivas e antidemocráticas, orientadas que são pela lógica competitiva das empresas (PARO, 2016).

Esse modelo gerencialista pressupõe monitoramento e tutela ao trabalho dos professores, com o auxílio de manuais e guias didáticos padronizados (ROSA, 2012). Estudo patrocinado pela UNESCO mostrou como orientações curriculares acentuadamente diretivas já estavam presentes em todo o Brasil no início da segunda década deste século. No entendimento das pesquisadoras: "A tendência é detalhar muito o que, como e quando deve ser ensinado e como deve ser avaliado, restringindo a autonomia do (a) professor (a) no manejo dos conteúdos escolares" (GATTI; BARRETO; ANDRÉ, 2011, p. 44). Em nome da qualidade, o clima competitivo que prevalece nas escolas relega a segundo plano as experiências significativas de aprendizagem, a formação de valores e atitudes necessárias para o convívio social democrático.

Mas definir qualidade por critérios quantitativos e meritocráticos é caminhar em sentido contrário ao entendimento de que educação é um bem público e direito fundamental de todos. Assumir essa perspectiva implica reposicionar o conceito de qualidade como qualidade social, em razão da função social da escola, o que equivale a dizer que uma educação de qualidade "é aquela que atenta para um conjunto de elementos e dimensões socioeconômicas e culturais 
que circundam o modo de viver e as expectativas das famílias e de estudantes em relação à educação" (SILVA, 2009, p. 225). Logo, faz-se necessário reposicionar também o conceito e as formas de avaliação do trabalho escolar.

Com base na ideia de "qualidade negociada" defendida por Freitas (2007), Antônio Flávio Moreira propõe que essa negociação seja feita, entre as escolas e os governos locais, via currículo. O autor defende a escola como espaço de crítica cultural e de pesquisa e nos dá pistas sobre como esse equilíbrio de forças pode ser buscado pela escola e pelos professores.

[...] ao participar do esforço por universalizar bens materiais e simbólicos necessários ao enfrentamento de problemas comuns, [o professor] precisa cruzar a fronteira entre o acadêmico e o político, o que exige sair do confortável terreno acadêmico e entrar em contato com o mundo exterior. (MOREIRA, 2013, p. 553, grifo nosso).

Neste trabalho, interessa-nos, particularmente, discutir em que medida e por meio de quais práticas o coordenador pedagógico pode ajudar seus pares a cruzar essa fronteira e pensar o trabalho educativo da escola de forma mais ampla e como fruto do engajamento coletivo em prol de um projeto comum

\section{COORDENADOR PEDAGÓGICO: ENTRE A GERÊNCIA E A MEDIAÇÃO}

Gatti, Barreto e André (2011) apontaram, em estudo já citado, o grande desafio dos gestores diante das excessivas prescrições que ferem a autonomia da escola e impõem obstáculos ao exercício da gestão democrática. Dizem elas:

O difícil equilíbrio sobre o que deve ser prescrito nos currículos no âmbito das redes públicas deve ser inicialmente balizado pelo diálogo com os docentes e estar sujeito a constantes revisões, tendo em vista a adequação às necessidades das escolas e da população diversificada a que atendem. (GATTI; BARRETO; ANDRÉ, 2011, p. 47).

Não se trata, portanto, de negar as relações de interdependência da escola com as esferas públicas às quais vincula, mas de buscar um equilíbrio entre as diretrizes gerais e as especificidades de cada unidade de ensino. Este é um trabalho que demanda abrir espaços de diálogo e criar estratégias para o engajamento de todos em torno de um projeto comum democraticamente negociado.

Implicar o corpo docente no processo decisório e no planejamento das ações consideradas prioritárias faz parte do processo de formação para a gestão democrática. Quando Nóvoa (2009) insiste na necessidade de que essa formação se dê no âmbito da escola, refere-se às condições que tornam o corpo docente corresponsável pelo trabalho escolar.

[...] é essencial reforçar dispositivos e práticas de formação de professores baseadas numa investigação que tenha como problemática a ação docente e o trabalho escolar. [...] Tratase, sim, de afirmar que as nossas propostas teóricas só fazem sentido se forem construídas dentro da profissão, se forem apropriadas a partir de uma reflexão dos professores sobre o seu próprio trabalho. Enquanto forem apenas injunções do exterior, serão bem pobres as mudanças que terão lugar no interior do campo profissional docente. (NÓVOA, 2009, p. 19)

Compete ao coordenador pedagógico criar esses dispositivos e práticas de que fala o autor, e não apenas ser o porta-voz das injunções que chegam de fora. Placco e Almeida (2006) insistem que a autoridade do coordenador como mediador exclui a coerção, o que implica que se posicione como guardião do respeito à autonomia docente e que promova espaços de 
diálogos indispensáveis à democracia como princípio da gestão. Organizar o tempo para a troca de experiências e construção de vínculos e compromissos comuns é outra importante atribuição do coordenador.

Nessa dinâmica, há de se aprender a respeitar e lidar com as diferentes visões de mundo e de educação, um trabalho de mediação que não é simples, mas que se justifica pela necessidade de que as ações convirjam para o projeto comum. É desse esforço que resultará um autêntico projeto político-pedagógico, desde que refletido, debatido e continuamente negociado com a comunidade escolar.

É nesse sentido que o trabalho do coordenador pedagógico assume um caráter político, na acepção dada a esse termo por Hannah Arendt. Para esta pensadora, a política é expressão daquilo que é público, que transcende os interesses particulares ou de uma geração. Diz ela: "Sem essa transcendência, para uma potencial imortalidade terrena, nenhuma política, no sentido restrito do termo, nenhum mundo comum e nenhuma esfera pública são possíveis" (ARENDT, 2001 p. 64).

Entendemos que a "qualidade negociada via currículo" de que fala Moreira (2013) começa pelo engajamento de todos na construção desse projeto, cuja mediação é uma das tarefas mais importantes a cargo do coordenador pedagógico. A experiência que passaremos a descrever e a comentar constituiu uma tentativa - a nosso ver fecunda - de criar as condições de possibilidade para a construção de um trabalho nessa perspectiva.

\section{A PESQUISA-AÇÃO COLABORATIVA NO CONTEXTO DE SÃO CAETANO DO SUL}

São Caetano do Sul (SCS) pode ser considerada uma cidade jovem. Foi fundada em 1877, por frades beneditinos e imigrantes italianos que se fixaram na região em busca de trabalho. Emancipada do município de Santo André, em 1947, foi palco do desenvolvimento industrial dos setores automobilístico, metalúrgico e químico, que atraíram para o ABC Paulista imigrantes de outras regiões do país, especialmente do Nordeste brasileiro. Conforme dados da Fundação SEADE (s.d.), SCS possuía, em 2017, 150.860 habitantes, que vivem em aproximadamente 15 km².

Embora figure no 1일 lugar no Índice de Desenvolvimento Humano por Município (IDH-M) de 2010, a desigualdade social é evidente: nas regiões do Rio dos Meninos, córrego que marca a divisa com São Bernardo do Campo e São Paulo, e do Rio Tamanduateí, onde se faz a divisa com Santo André, encontramos uma população vulnerável, literalmente marginalizada, que contrasta com as casas amplas e bem conservadas do bairro Barcelona, um dos mais tradicionais da cidade. Uma frase comumente utilizada pelos munícipes caracteriza o clima de convivência na cidade: "Aqui todo mundo se conhece".

A rede municipal de ensino de SCS conta com 16 Escolas Municipais Integradas (EMIs), que oferecem Educação Infantil em período integral; 22 Escolas de Educação Infantil (EMEls) e três creches conveniadas; 20 Escolas Municipais de Ensino Fundamental (EMEFs), sete delas em tempo integral; e três com Ensino Fundamental e Médio. Segundo a prefeitura², SCS é "referência nacional no ensino público de qualidade, com índices de escolaridade comparáveis a de países de Primeiro Mundo". Já em relação à gestão democrática, estudos de Garcia et al. (2015) informam que neste município se situam as escolas mais centralizadoras da região e as que menos criam possibilidades de participação da comunidade.

\footnotetext{
${ }^{2}$ Disponível em: http://www.saocaetanodosul.sp.gov.br/a-cidade.html.
} 
Com o objetivo de conhecer o perfil profissional e de formação dos coordenadores pedagógicos (CPs), utilizamos algumas questões do questionário contextual dos diretores da Prova Brasil 2013, aplicadas ao grupo de 14 CPs que atuavam exclusivamente nos anos finais do Ensino Fundamental, em 2016. A coleta dos dados ocorreu em um dos encontros regulares promovidos pelo Centro de Capacitação de Profissionais da Educação Dra. Zilda Arns (CECAPE), órgão vinculado à Secretaria de Educação do município, com autorização de todos os participantes.

Alguns dados chamaram a atenção: a maioria dos CPs são mulheres (83\%), com idade entre 30 e 49 anos (67\%); todos possuem graduação na área de educação (58\% em Pedagogia), obtida há no máximo 14 anos, o que revela uma formação acadêmica relativamente recente; $25 \%$ possuem mestrado e outros $25 \%$ alguma pós-graduação lato sensu; $67 \%$ possuem experiência docente entre 3 e 10 anos e ocupavam a função de CP há no máximo 5 anos. A explicação para este último dado é de que o acesso aos cargos de direção e coordenação pedagógica, em SCS, dá-se por indicação política ou técnica.

Quanto à rotina de trabalho, as atividades que mais ocupam esses profissionais são: 83\% para o atendimento de pais de alunos; 75\% para mediação de conflitos e/ou indisciplina de alunos; $67 \%$ na preparação de atividades de formação para a Hora de Trabalho Pedagógico Coletivo (HTPC); e 58\% no auxílio aos professores na elaboração de aulas e outras atividades. Vale ressaltar que, de acordo com o regimento escolar, as duas primeiras (atendimento aos pais e mediação de conflitos) são atribuições do orientador educacional, porém, na prática, todos são acionados para dar conta das urgências do cotidiano escolar. Daí ser comum que os coordenadores se vejam como "apagadores de incêndio".

Diante disso, os CPs indicaram que suas maiores dificuldades e desafios são: a) dar conta do excesso de trabalho burocrático e das solicitações externas; b) suprir a falta de professores e/ou funcionários; c) controlar a ansiedade, por se sentirem "responsáveis por tudo"; d) saber lidar com (a falta de) tempo. Os dados desse mapeamento inicial foram problematizados com a equipe pedagógica da escola em que a pesquisadora atuava como CP e onde se realizou a pesquisa-ação que passaremos a relatar.

Participaram da etapa qualitativa da pesquisa, realizada em 2016: cinco professores coordenadores de área (CA) - que são docentes que auxiliam o CP em áreas específicas do currículo dos anos finais do Ensino Fundamental - e outros três professores dos anos finais do EF, que voluntariamente integraram o grupo de trabalho. Não apenas para atender os princípios éticos, mas por ser um pressuposto epistemológico da pesquisa, todos os colaboradores assinaram o Termo de Consentimento Livre e Esclarecido (TCLE), do qual constavam os objetivos do trabalho e o uso estritamente acadêmico dos registros das sessões reflexivas.

De acordo com Ibiapina (2008), as sessões reflexivas, como procedimento da pesquisa-ação, visam criar condições para que os colaboradores ressignifiquem suas práticas cotidianas a partir de uma compreensão mais aprofundada sobre determinantes históricos, sociais e filosóficos do seu próprio trabalho. Esse não é um processo simples, pois as visões que orientam as ações cotidianas são, em geral, impregnadas de mal-entendidos, equívocos e, até mesmo, de preconceitos. Daí a necessidade de um rigoroso planejamento das sessões para dar suporte teórico e consistência às reflexões do grupo.

[...]. Sem o apoio conceitual e teórico da investigação educativa e da reflexão sistemática e compartilhada sobre a prática, o processo de socialização do professorado e de aprendizagem com a categoria reproduz facilmente em seu pensamento, e em sua prática, os vícios, os 
preconceitos [...] sob a pressão onipresente da cultura pedagógica dominante e das exigências que a instituição escolar impõe. (GÓMEZ PÉREZ, 1998, p. 364).

O roteiro e o conteúdo das seis sessões reflexivas, realizadas durante o horário coletivo de trabalho pedagógico, foram organizados em quatro eixos (momentos) que nortearam as discussões: a) Descrição: quem somos? O que fazemos? Por que fazemos assim?; b) Informação: a escola que temos e a escola que queremos; c) Confronto: nossas urgências $x$ qualidade pretendida; d) Reconstrução: quebrando paradigmas: reconstrução crítica de práticas e conceitos.

Com o consentimento dos participantes, as discussões foram gravadas em áudio e posteriormente transcritas para serem analisadas. A análise do conjunto desses registros teve por base a abordagem teórico-metodológica dos Núcleos de Significação (AGUIAR; OZELLA, 2006), fundamentada na perspectiva epistemológica sócio-histórica. Nessa abordagem, o conteúdo das falas (e silêncios) não é apenas descrito pelo pesquisador; o que se busca é apreender os sentidos e significados atribuídos pelos sujeitos, como síntese das determinações sociais e subjetivas em que foram produzidos.

Não cabe aqui detalhar os fundamentos e a forma de tratamento dos dados dessa abordagem, mas vale esclarecer que no trabalho de organização dos núcleos "[...] - que tem como critério a articulação de conteúdos semelhantes, complementares e/ou contraditórios -, é possível verificar as transformações e contradições que ocorrem [nesse] processo..." (AGUIAR; OZELLA, 2013, p. 310). A síntese dessa elaboração é o que passaremos a discutir.

\section{Núcleo 1 - Escassez de tempo e identidade frágil: o grupo precisa de mudanças}

Um tema recorrente em todas as sessões foi a discrepância entre as atribuições dos coordenadores de área (CA), definidas no Regimento Escolar, e as tarefas com as quais se ocupam no dia a dia, "apagando incêndios". A maioria, aliás, desconhecia esse documento e que a eles competia colaborar com o trabalho pedagógico de seus pares. Esse fato por si só explica por que a identidade desses profissionais é tão frágil, fragilidade que aparece na dificuldade que têm em definir prioridades e organizar seu tempo de trabalho.

Eu tenho a impressão que a gente não se aprofunda em nada porque a gente não tem certeza das nossas prioridades [...] porque nem consegue dizer o que é mais importante.

Não deu tempo de ver tudo, nunca dá, a gente programa e nunca dá.

A "falta de tempo" se deve, em grande parte, à incansável busca por melhores resultados. Os desabafos dessas falas confirmam constatações observadas na primeira etapa deste estudo:

A educação vive muito em busca do resultado. Você tem que fazer esse projeto ontem, porque ele tem que ser publicado, ele tem que mostrar [o resultado] para alguém.

A educação virou balanço. O currículo também parece que não foi muito bem pensado, você joga uma quantidade absurda de conteúdos para serem trabalhados por trimestre [...] depois o outro fica mais vazio no final, e assim vai.

Dessas discussões, emergiu a consciência de uma das mudanças mais urgentes: reduzir o volume de trabalho burocrático da escola (preenchimento de fichas, documentos, planilhas), pois o tempo despendido em tais tarefas subverte as prioridades e o sentido do trabalho da coordenação pedagógica. 


\section{Núcleo 2 - Trabalhar juntos: estratégias para transformar a prática}

Quando os participantes foram confrontados com a questão sobre o que fazer para mudar, propostas surgiram na direção de uma maior integração e comunicação entre os professores. Sugestões simples e bastante pragmáticas - como concentrar informações da rotina da escola em um só local - demonstraram o despertar e a disposição de professores para pensar com a equipe gestora formas colaborativas de organização dos espaços e materiais de uso comum.

Eu acho que na escola tudo deveria ser sistematizado [organizado]. Tudo teria que ter como funciona, com quem se fala.

Quanto ao trabalho pedagógico em sala de aula, "soluções" como "montar um banco de ideias" e de "boas práticas" que pudessem ser "multiplicadas" por outros professores da mesma área denotam um fato curioso: tais expressões - comuns à retórica dos programas de formação continuada da gestão municipal para "gerar bons resultados" - já foram assimiladas aos discursos e ao universo de representações dos docentes. O pragmatismo a elas inerente aparece em comentários como: "Basta que se tenha boa vontade!" ou "Isso pode facilitar o nosso trabalho". Falas como essas são indicativas do quanto os discursos oficiais definem o significado de qualidade como também o sentido de educação que vai se fixando na subjetividade dos profissionais da escola.

Mas convivem com essas ideias performáticas uma genuína disposição do grupo de trocar experiências, a valorização do diálogo e a expectativa de contarem com a ajuda dos colegas para melhorarem as aulas. É preciso dizer que, em São Caetano do Sul, a orientação recebida da Secretaria de Educação é de que os coordenadores observem as aulas dos professores e, em seguida, apresentem um feedback individual, como parte do trabalho de "acompanhamento" docente e da "formação em serviço".

Mas o sentimento dos professores é de que os coordenadores deveriam "ficar de fora", "para tirar um pouco o peso" das observações e para que as aulas observadas não se transformem em um "show", em algo "que não é real". O sentido subjacente a essas manifestações revela a percepção do caráter performático dessas práticas e que os "gestores" (coordenadores) são vistos como fiscais, e não como colaboradores. Fortalecer os vínculos e as relações de confiança entre os pares aparece, assim, como condição para o trabalho colaborativo da equipe.

\section{Núcleo 3 - Avanços a partir da gestão democrática e da formação docente}

Este núcleo, de algum modo, sintetiza os principais achados desta pesquisa. Alguns pontos merecem destaque. Ao longo das sessões, foi ficando claro o quanto o grupo já está "convencido" da "necessidade" de ser monitorado. No entanto, transparece também o desconforto por sentirem que o trabalho que desenvolvem em sala de aula é alvo de constante julgamento e vigilância. Como uma espécie de saída conciliatória, o grupo arrisca sugerir a elaboração de uma "nova matriz de observação", pensada e negociada com os docentes.

Ainda que de forma tímida e cuidadosa, o grupo deu sinais importantes sobre a importância de criar espaços de diálogo e de estabelecer vínculos de confiança para que a escola "avance como um todo". Reflexões interessantes a respeito do significado atribuído ao diálogo merecem ser destacadas.

Como criar um ambiente saudável [na escola] sem diálogo?

Será que eu quero conversar com a família ou será que eu quero que a família me atenda no

INTERAÇÕES, Campo Grande, MS, v. 21, n. 1, p. 81-92, jan./mar. 2020 
que eu preciso para que a criança aprenda? Isso é diálogo mesmo? Ele vai escutar a família ou ele quer ser escutado?

Quando associamos essas impressões com as insistentes reclamações de falta de tempo e de espaços de diálogo nas escolas, podemos pensar que o princípio da "gestão democrática" tem sido apenas um elemento de retórica. A experiência de trabalho colaborativo realizada nessa escola indica que investir na aproximação da coordenação pedagógica com os docentes é um caminho não apenas possível, mas promissor, para pavimentar a construção de uma outra referência de qualidade para o trabalho escolar. Uma qualidade negociada, que respeite o ritmo dos professores no processo de (re)construção de sua autonomia profissional e emancipação intelectual.

\section{CONSIDERAÇÕES FINAIS}

Dissemos, na abertura deste texto, que a intensificação do trabalho docente, o tempo estrangulado e a falta de espaços de diálogo fazem parte de uma realidade vivida por quase todas as escolas brasileiras. Apontamos também que as políticas regulatórias que tendem a padronizar os processos de gestão, os currículos e os resultados de desempenho dos alunos subvertem o sentido da educação.

Para tratar desse tema mais amplo, focalizamos o trabalho do coordenador pedagógico, pressionado entre as demandas externas, as urgências da escola e a consciência de sua responsabilidade como mediador. Argumentamos que, quando o projeto político-pedagógico é obscurecido pelas regras e imposições externas, é preciso que os profissionais se posicionem e busquem uma qualidade negociada, que priorize as necessidades sociais dos alunos e respeite o direito de todos à educação, entendida como bem público, e não como "serviço" a ser avaliado com critérios análogos aos bens de consumo. Assim, constatamos que o grande desafio do CP é abrir e sustentar espaços de diálogo, criando estratégias de engajamento colaborativo de todos em torno de um projeto comum. A pesquisa-ação colaborativa relatada neste texto teve a pretensão de ensaiar alguns passos nessa direção.

Embora São Caetano do Sul seja considerada uma cidade privilegiada, tanto do ponto de vista socioeconômico como dos indicadores - oficiais - de qualidade, podemos dizer agora que, em se tratando de gestão democrática da escola, o município tem ainda muito o que caminhar. Resultou da análise de nossos registros a constatação do quanto a ausência de espaços de diálogo mantém represados os mecanismos de participação docente nas decisões dos rumos da escola e de seu próprio trabalho.

Concluímos que a alegada tarefa primordial do coordenador pedagógico de promover a formação continuada dos professores no âmbito da escola só faz sentido se intimamente articulada a um projeto político-pedagógico construído de forma reflexiva e negociada e em função de uma qualidade de educação que só pode ser adjetivada de "social" se, primeiro, for entendida como bem público e, segundo, se for forjada em ambiente solidário e democrático. 


\section{REFERÊNCIAS}

AGUIAR, Wanda Maria Junqueira de; OZELLA, Sergio. Apreensão dos sentidos: aprimorando a proposta dos núcleos de significação. Revista Brasileira de Estudos Pedagógicos, Brasília, DF, v. 94, n. 236, p. 299-322, jan./abr. 2013. Disponível em: http://www.scielo.br/pdf/rbeped/v94n236/15.pdf. Acesso em: 23 mar. 2018

ANDERSON, Gary. Privatizando subjetividades: como a Nova Gestão Pública (NGP) está criando um "novo" profissional da educação. RBPAE - Revista Brasileira de Política e Administração na Educação, v. 33, n. 3, p. 593-626, set./dez. 2017.

ARENDT, Hanna. A Condição Humana. Trad. de Roberto Raposo, posfácio Celso Lafer. 10. Ed. Rio de Janeiro: Forense Universitária, 2001.

ARROYO, Miguel G. Administração da educação, poder e participação. Educação e Sociedade, Campinas, SP, v. 1, n. 2, p. 36-46, 1979.

BALL, Stephen J. Global education Inc.: new policy networks and the neo-liberal imaginary. London \& New York: Routledge, 2012.

BALL, Stephen J. Profissionalismo, gerencialismo e performatividade. Cadernos de Pesquisa, São Paulo, v. 35, n. 126, p. 539-64, set./dez. 2005.

BONAMINO, Alicia; SOUSA, Sandra Zákia. Três gerações de avaliação da educação básica no Brasil: interfaces com o currículo da/na escola. Educação e Pesquisa, São Paulo, v. 38, n. 2, p. 373-88, abr./jun. 2012.

CARR, Wilfred; KEMMIN, Stephen. Teoría crítica de la enseñanza: la investigación-acción en la formación del profesorado. Barcelona: Ediciones Martines Roca, 1988.

FÉLIX, Maria de Fátima Costa. Administração escolar: um problema educativo ou empresarial? São Paulo: Cortez/Autores Associados, 1984.

FREIRE, Paulo. Pedagogia da autonomia. São Paulo: Paz e Terra, 1997.

FREITAS, Luiz Carlos de. Os reformadores empresariais da educação e a disputa pelo controle do processo pedagógico na escola. Educação \& Sociedade, Campinas, SP, v. 35, n. 129, p. 1085-114, out./dez. 2014.

FREITAS, Luiz Carlos. Eliminação adiada: o caso das classes populares no interior da escola e a ocultação da (má) qualidade do ensino. Educação \& Sociedade, Campinas, SP, v. 28, n. 100, p. 965-87, out. 2007.

FUNDAÇÃO SEADE. Fundação Sistema Estadual de Análise de Dados. Portal de Estatísticas do Estado de São Paulo, s.d. Disponível em: https://www.seade.gov.br.

GARCIA, Paulo Sérgio; PREARO, Leandro Campi; ROMERO, Maria do Carmo; BASSI, Marcos Sidnei. Formação, atuação e formas de gestão dos diretores de escola da Região do ABC. In: GARCIA, Paulo Sérgio; PREARO, Leandro (Org.). Avaliação da educação escolar no Grande ABC Paulista: primeiras aproximações. São Paulo: Plêiade, 2015. p. 149-81.

GATTI, Bernardete Angelina; BARRETO, Elba Siqueira de Sá; ANDRÉ, Marli E. D. Afonso. Políticas docentes no Brasil: um estado da arte. Brasília: Unesco, 2011. p. 31-48. Disponível em: http://unesdoc.unesco.org/ images/0021/002121/212183por.pdf. Acesso em: maio 2016.

GÓMEZ PÉREZ, Ángel I. La cultura escolar en la sociedad neoliberal. Madrid: Ediciones Morata, 1998. IBIAPINA, Ivana Maria Lopes de Melo. Pesquisa colaborativa: investigação, formação e produção de conhecimentos. Brasília: Líber Livro, 2008. 
MOREIRA, Antônio Flavio Barbosa. Currículo e gestão: propondo uma parceria. Ensaio: Avaliação e Políticas Públicas em Educação, Rio de Janeiro, v. 21, n. 80, p. 547-62, set. 2013.

NÓVOA, António. Imagens do futuro presente. Lisboa, Portugal: Educa, 2009.

PARO, Vitor Henrique. Gestão democrática da escola pública. São Paulo: Ática, 2016.

PLACCO, Vera Maria Nigro de Souza; ALMEIDA, Laurinda Ramalho (Org.). O coordenador pedagógico e o cotidiano da escola. São Paulo: Edições Loyola, 2006.

ROSA, Sanny Silva. Reformas educacionais e pesquisa: as políticas "em cena" no Brasil e na Inglaterra. Revista e-Curriculum, São Paulo, v. 9, n. 2, p. 1-28, ago. 2012.

SILVA, Maria Abádia da. Qualidade social da educação pública: algumas aproximações. Cadernos CEDES, v. 29, n. 78, p. 216-26, maio/ago. 2009.

SOLIGO, Valdecir. Possibilidades e desafios das avaliações em larga escala da educação básica na gestão escolar. Revista online de Política e Gestão Educacional, Araraquara, SP, n. 9, 2010. Disponível em: https:// periodicos.fclar.unesp.br/rpge/article/view/9275/6152. Acesso em: 23 mar. 2018.

VIDAL, Eloisa Maia; VIEIRA, Sofia Lerche. Gestão educacional e resultados no Ideb: um estudo de caso em dez municípios cearenses. Estudos em Avaliação Educacional, São Paulo, v. 22, n. 50, p. 419-34, set./ dez. 2011.

ZEICHNER, Kenneth M. A formação reflexiva de professores: ideias e práticas. Lisboa, Portugal: Educa, 1993.

\section{Sobre as autoras:}

Vanessa Maria Vicente Umemura: Pedagoga e mestre em Educação pela Universidade Municipal de São Caetano do Sul (USCS). Professora de Educação Infantil e do Ensino Fundamental. Assistente de direção na rede municipal de ensino de São Caetano do Sul. Entre 2014 e 2017, atuou como coordenadora pedagógica do Ensino Fundamental II. E-mail: vanessaumemura.leandroklein@gmail.com, Orcid: http://orcid.org/0000-0002-1733-5785

Sanny Silva da Rosa: Doutora em Educação (Currículo) pela PUC-SP. Estudos de pós-doutoramento em Políticas Educacionais - Instituto de Educação da Universidade de Londres, Reino Unido. Pesquisadora do Mestrado Profissional em Educação da Universidade Municipal de São Caetano do Sul (USCS). E-mail: sanny.rosa@prof.uscs.edu.br, Orcid: http://orcid.org/0000-0001-5044-6156 